\title{
Formation and Growth of Intermetallics around Metallic Particles in Eutectic Sn-Ag Solder
}

\author{
J.G. LEE, ${ }^{1}$ K.C. CHEN, ${ }^{2}$ and K.N. SUBRAMANIAN ${ }^{1,3}$ \\ 1.-Department of Chemical Engineering and Materials Science, Michigan State University, East \\ Lansing, MI 48824. 2.-Materials Engineering Department, California Polytechnic State Univer- \\ sity, San Luis Obispo, CA, 93407. 3.—subraman@egr.msu.edu
}

\begin{abstract}
Incorporation of metallic particulate reinforcements in eutectic Sn-Ag solder results in the formation of intermetallic compounds (IMCs) along particulate/ solder interfaces with different morphologies. For instance, "sunflower" and "blocky faceted" IMC shapes have been observed around Ni particle reinforcements incorporated in the eutectic Sn-Ag solder matrix. The time and temperature above solder liquidus during the heating stage of the reflow process has been found to play a significant role in determining the IMC morphology in these Ni particulate-reinforced solders. Similar studies were carried out with $\mathrm{Cu}$ and $\mathrm{Ag}$ particulate reinforcements using the same solder matrix. The amount of heat input caused no significant change in morphology of the IMCs formed around $\mathrm{Cu}$ and $\mathrm{Ag}$ particulate reinforcements. Also, the IMC morphology around $\mathrm{Ni}$ particles was sensitive to the $\mathrm{Cu}$ content in the solder, whether the $\mathrm{Cu}$ came from the substrate during reflow or it was already present within the solder.
\end{abstract}

Key words: Lead-free composite solder, intermetallic morphology, metallic particle reinforcements

\section{INTRODUCTION}

Intermetallic compounds (IMCs) formed both at the solder/substrate interface and within the solder during reflow exhibit different morphological features depending on the conditions employed. Significant efforts have been devoted to characterize solder/substrate interface IMCs. ${ }^{1-5}$ The brittle nature of IMCs formed at the solder/substrate interface and their potential to degrade the mechanical performance of the solder joints provides the main impetus to study these compounds. However, it has been clearly documented in several studies that catastrophic failure caused by thermomechanical fatigue or creep occurs by crack growth within the solder near the solder/substrate interface, not in the interface IMC layer. ${ }^{6,7}$

The composite solder approach has been demonstrated to be a viable means to achieve better service performance, particularly, in lead-free solders. ${ }^{8-12}$ Such solders may contain a IMC produced either by in-situ methods ${ }^{8,9}$ or mechanically incorporated, metallic particles, which upon reflow completely or partially transform into IMCs. ${ }^{10-12}$ Ternary and quaternary alloys being considered for enhanced service performance also derive their better attributes because of IMC particles present within the solder. Significantly different morphologies of the IMC that form around $\mathrm{Ni}$ particles present within the eutectic 96.5Sn-3.5Ag (wt.\%) solder matrix have been observed. These morphologies were dependent on the reflow conditions. ${ }^{13}$ Incidentally, these morphological features, which develop during reflow, will differ between the reinforcements. ${ }^{14,15}$ The $\mathrm{Ni}$ particlereinforced solder showed change in the morphology of the IMC around the Ni particles as a consequence of an imposed reflow profile. Depending on time and temperature above solder liquidus during reflow, sunflower or blocky morphology of the IMC was noted. The strong role of time and temperature above solder liquidus during reflow, especially during the heating segment, in development of sunflower morphologies into blocky morphologies has been documented in an earlier study. ${ }^{13}$ 
The goal of the present study was to compare the morphology of the IMC formed around the metallic reinforcements, $\mathrm{Ag}, \mathrm{Cu}$, and $\mathrm{Ni}$, contained in the $\mathrm{Sn}-\mathrm{Ag}$ solder so as to gain a better understanding of parameters that contribute to various IMC morphologies.

\section{EXPERIMENTAL PROCEDURE}

The appropriate amount of $\mathrm{Ni}, \mathrm{Cu}$, or $\mathrm{Ag}$ metallic particles was added to eutectic 96.5Sn-3.5Ag (wt.\%) solder paste to introduce about 20 vol.\% of the IMC in the solder matrix. The percentage of the IMC was calculated assuming that the entire metallic particles are converted into IMC, without correcting for the decrease in $\mathrm{Sn}$ in the solder caused by the formation of this IMC. The size of the $\mathrm{Ag}, \mathrm{Ni}$, and $\mathrm{Cu}$ metallic particles were about $1 \mu \mathrm{m}, 5 \mu \mathrm{m}$, and $10 \mu \mathrm{m}$, respectively. The metallic particles and the solder paste were mixed thoroughly for about 20 min to provide uniform distribution of reinforcements prior to reflow. Two half dog-bone-shaped $\mathrm{Cu}$ substrates with $0.5-\mathrm{mm}$ thickness and $1-\mathrm{mm}^{2}$ solder area were sandwiched with the composite solder pastes to fabricate single shear-lap solder joints. Details of this solder joint configuration and experimental details for making the joint can be found elsewhere. ${ }^{6,12}$

\section{Reflow Studies}

To monitor changes in IMC morphology resulting from different, reflow thermal histories, seven different reflow profiles were employed. First, a fixed cooling rate of $0.9^{\circ} \mathrm{C} / \mathrm{sec}$ was used. The reflow profiles used in this study were (1) a fast heating rate $\left(5^{\circ} \mathrm{C} / \mathrm{sec}\right),(2)$ a fast heating rate with a higher peak temperature, (3) a medium heating rate $\left(2.6^{\circ} \mathrm{C} / \mathrm{sec}\right)$, and (4) a slow heating rate $\left(0.8^{\circ} \mathrm{C} / \mathrm{sec}\right)$. The peak temperature reached in conditions (1), (3), and (4) was $280^{\circ} \mathrm{C}$, while that in (2) was $320^{\circ} \mathrm{C}$. All these specimens were cooled on an aluminum block after reaching the chosen peak temperature.

In the second part of this study, four different reflow-cooling rates with a fixed fast heating rate $\left(5^{\circ} \mathrm{C} / \mathrm{sec}\right)$ were used in the temperature profiles. These profiles were (1) the fastest cooling rate (cooled in water: $8.5^{\circ} \mathrm{C} / \mathrm{sec}$ ), (2) a fast cooling rate (cooled on aluminum block: $0.9^{\circ} \mathrm{C} / \mathrm{sec}$ ), (3) a medium cooling rate (cooled on firebrick: $0.4^{\circ} \mathrm{C} / \mathrm{sec}$ ), and (4) the slowest cooling rate (cooled on wood: $0.1^{\circ} \mathrm{C} / \mathrm{sec}$ ). Time-temperature profiles for these different reflow conditions can be found in an earlier publication. ${ }^{13}$

\section{Aging Studies}

To investigate change in IMC morphology around $\mathrm{Ni}$ particles during solid-state aging, joints were aged at $150^{\circ} \mathrm{C}$ for $50 \mathrm{~h}$ and at $200^{\circ} \mathrm{C}$ for $2 \mathrm{~h}$ and $20 \mathrm{~h}$. Isothermal aging was also carried out at $230^{\circ} \mathrm{C}$ and $250^{\circ} \mathrm{C}$ in the presence of the molten solder. All these treatments employed fast heating rate and fast cooling rate.

\section{Substrate Effects}

Copper and nickel substrates were used for solders containing only the Ni particle. The Ni substrate was used for the solder containing both $\mathrm{Cu}$ and $\mathrm{Ni}$ particles to avoid $\mathrm{Cu}$ pickup from the substrate. $\mathrm{A} \mathrm{Cu}$ substrate was used for the solders containing either Ag or $\mathrm{Cu}$ particles as the only reinforcement.

The side surfaces of the solder joints were metallurgically polished to reveal the development of the morphological features of the IMC.

\section{RESULTS AND DISCUSSION}

\section{Intermetallic Compound Morphology around $\mathrm{Ag}$ and $\mathrm{Cu}$ Particles after Different Reflow Profiles}

Although the prior study ${ }^{13}$ dealt with IMC morphology around Ni particles in eutectic 96.5Sn-3.5Ag solder with various reflow conditions, to investigate the IMC morphology around metallic particulate reinforcements, such as $\mathrm{Ag}$ and $\mathrm{Cu}$, the same reflow profiles were provided in the Experimental Procedure section.

As can be observed in Fig. 1, Ag particle-reinforced solder joints did not exhibit a change in morphology of the IMC formed around Ag particles because of the different thermal histories imposed. A very thin layer of $\mathrm{Ag}_{3} \mathrm{Sn}$ IMC formed around $\mathrm{Ag}$ particles and the shape and size of these Ag particles and the IMC did not alter either with different cooling rates or with different heating rates. A multiple reflow study on the Ag composite solder had shown that no significant change occurred in the IMC morphology, even after four reflows. ${ }^{15}$

The $\mathrm{Cu}$ particle-reinforced solder joints were also prepared with different thermal-reflow histories just as in the case of the $\mathrm{Ni}$ and $\mathrm{Ag}$ particle-reinforced composite solders. The IMC morphology of the $\mathrm{Cu}$ composite solder joints was not affected by either different cooling rates or different heating rates, as illustrated in Fig. 2. The IMC morphology around $\mathrm{Cu}$ particles was sunflower shaped with thick petal arms. No significant change in IMC morphology was noted in the previous study that used multiple reflows. ${ }^{15}$

\section{Solid-State Aging of Ni Particle-Reinforced Composite Solder Joints}

The Ni-composite solder joints were made with a fast heating and a fast cooling rate to give the sunflower IMC morphology around the $\mathrm{Ni}$ particles. Then, these samples were aged at $150^{\circ} \mathrm{C}$ and $200^{\circ} \mathrm{C}$ to investigate the effect of solid-state diffusion on the further development of any of the IMC morphology.

The effect of isothermal aging at $150^{\circ} \mathrm{C}$ is illustrated in Fig. 3. The same field of view (targeted area) was observed after different aging times. No significant visible difference in the morphology of the IMC developed as a consequence of this aging process. Even at a higher aging temperature of 

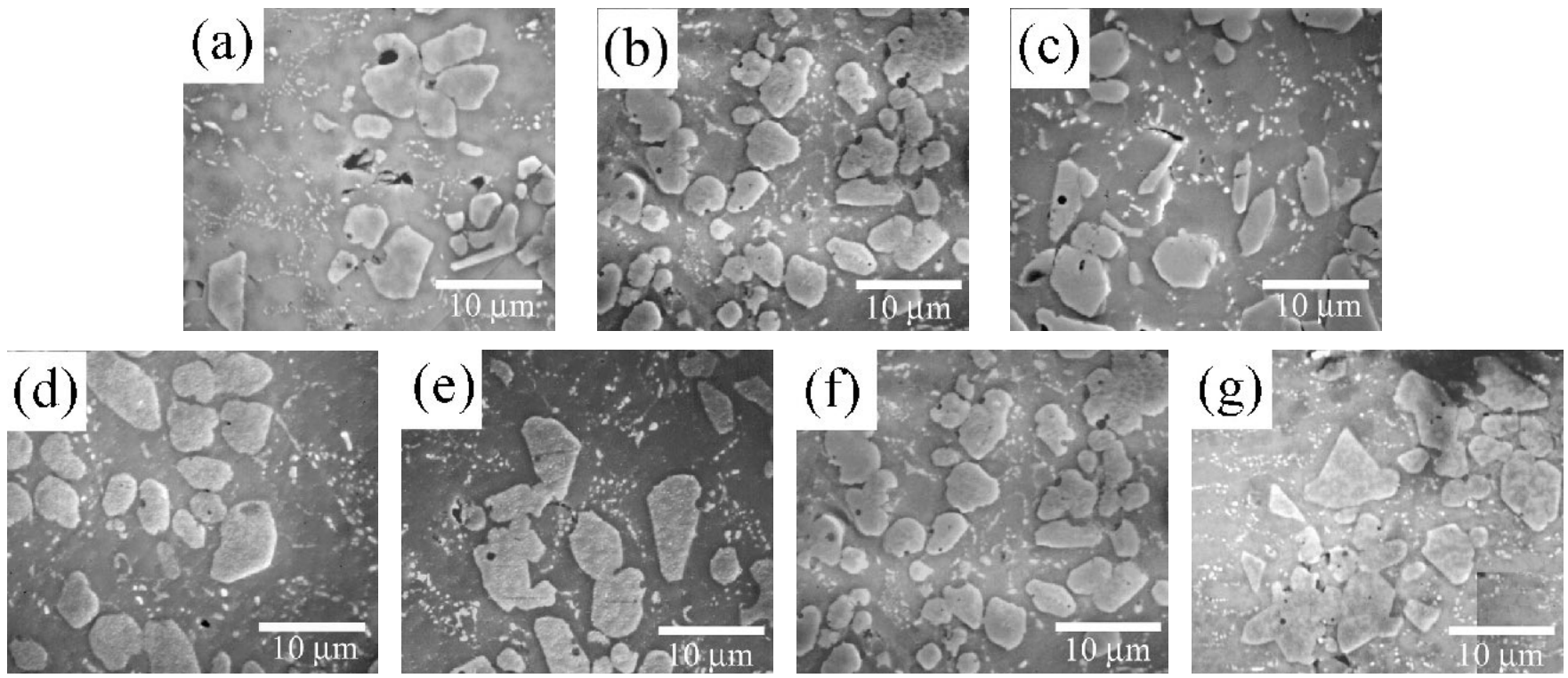

Fig. 1. The IMC morphology in the Ag composite solder after reflows with different cooling rates ((a)-(d) fixed fast heating rate): (a) the fastest cooling rate, (b) fast cooling rate, (c) slow cooling rate, and (d) the slowest cooling rate. The IMC morphology of the Ag-composite solder after reflows with different heating rates $\left((\mathrm{e})-(\mathrm{g})\right.$ fixed fast cooling rate): (e) fast heating rate at higher peak temperature $\left(330^{\circ} \mathrm{C}\right)$, (f) medium heating rate, and $(\mathrm{g})$ slow heating rate.
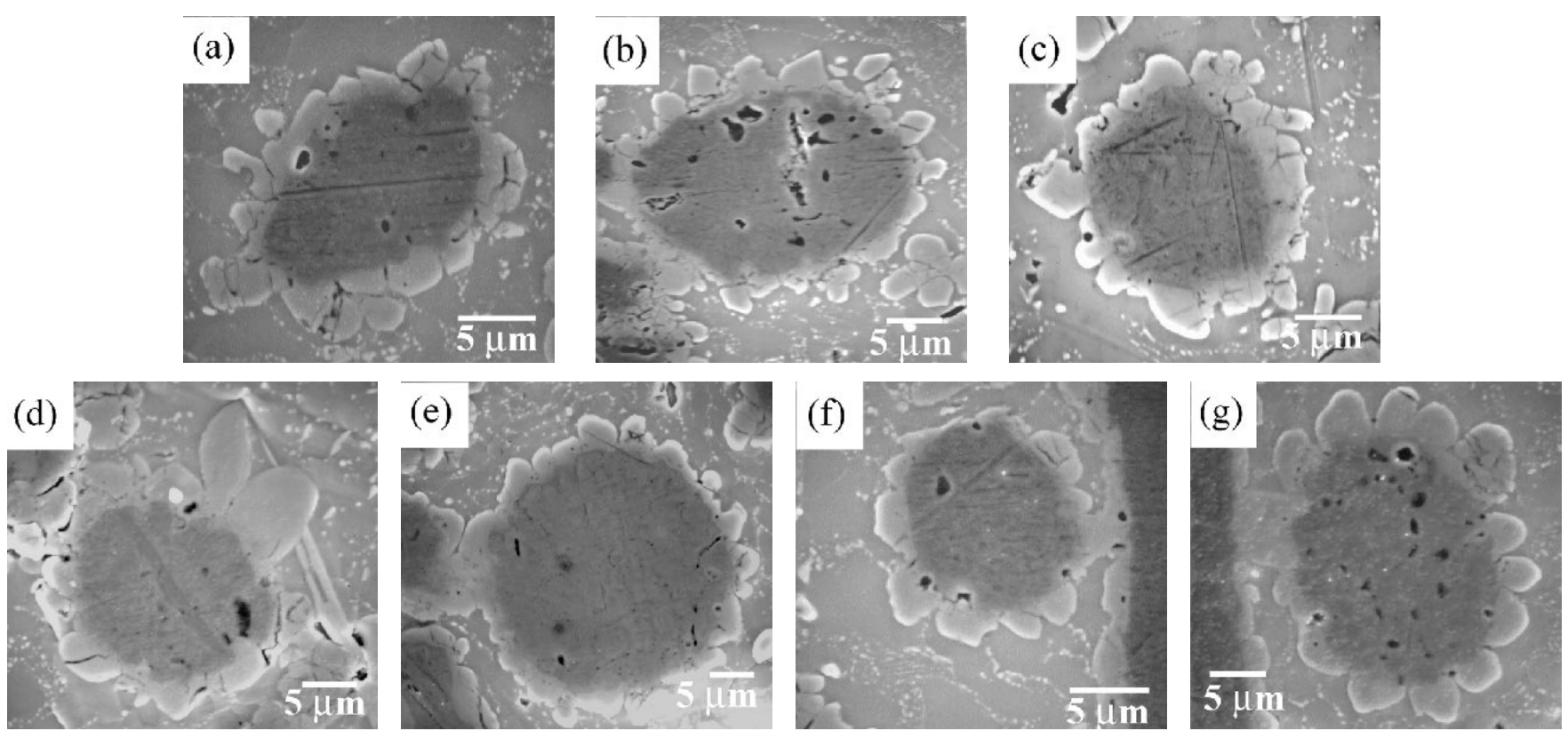

Fig. 2. The IMC morphology in the Cu composite solder after reflows with different cooling rates ((a)-(d) fixed fast heating rate): (a) the fastest cooling rate, (b) fast cooling rate, (c) slow cooling rate, and (d) the slowest cooling rate. The IMC morphology of the Cu composite solder after reflows with different heating rates $\left((\mathrm{e})-(\mathrm{g})\right.$ fixed fast cooling rate): (e) fast heating rate at higher peak temperature $\left(320^{\circ} \mathrm{C}\right),(\mathrm{f})$ medium heating rate, and $(\mathrm{g})$ slow heating rate.

$200^{\circ} \mathrm{C}$, no change in IMC morphology occurred, as seen in the series of micrographs shown in Fig. 4.

\section{Effect of Isothermal Aging in the Presence of Molten Solder at $230^{\circ} \mathrm{C}$ and $250^{\circ} \mathrm{C}$}

\section{Solder with Ni Particle Reinforcement}

The effect of isothermal aging at a temperature above the melting temperature of the eutectic 96.5Sn-3.5Ag solder was carried out to observe changes in IMC morphology around $\mathrm{Ni}$ particles.
The substrate used in this particular experiment was a $\mathrm{Cu}$ substrate because the sunflower IMC morphology developed during reflow on this substrate with Ni particle-reinforced composite solder. ${ }^{13}$ The IMC morphology around Ni particles starts with a very thin IMC layer after a short period of time (Fig. 5a), and the long petal arms of sunflower morphology forms after longer hold times (Fig. 5b). The morphological changes to the IMC occurred much faster at $250^{\circ} \mathrm{C}$. The IMC became blocky after about $200 \mathrm{sec}$ at this temperature. 

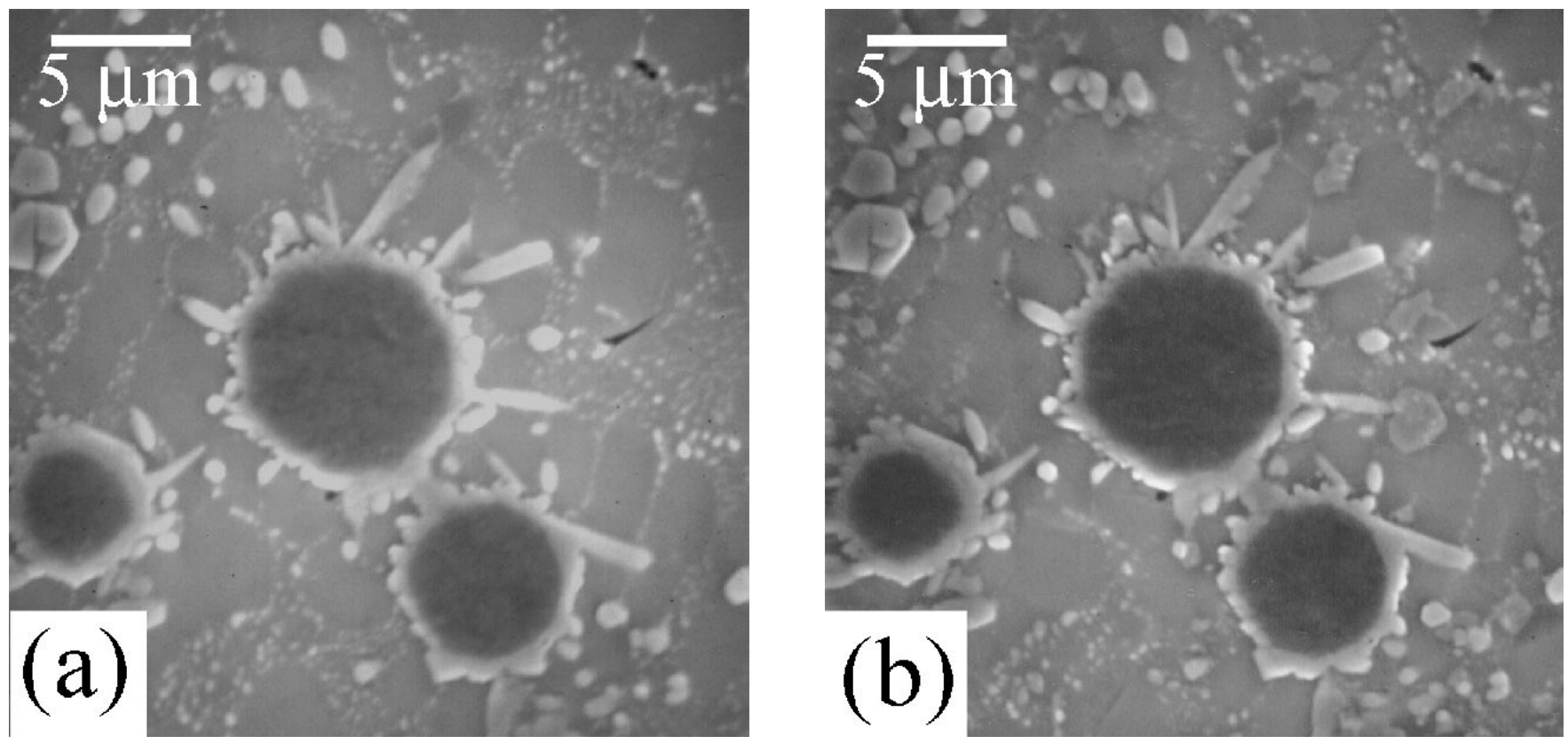

Fig. 3. The effect of isothermal aging at $150^{\circ} \mathrm{C}$ on IMC morphology in the Ni-reinforced composite solder joint: (a) as-fabricated and (b) after 50 h. No change in IMC morphology can be noted. Note: fast heating rate and fast cooling rate.

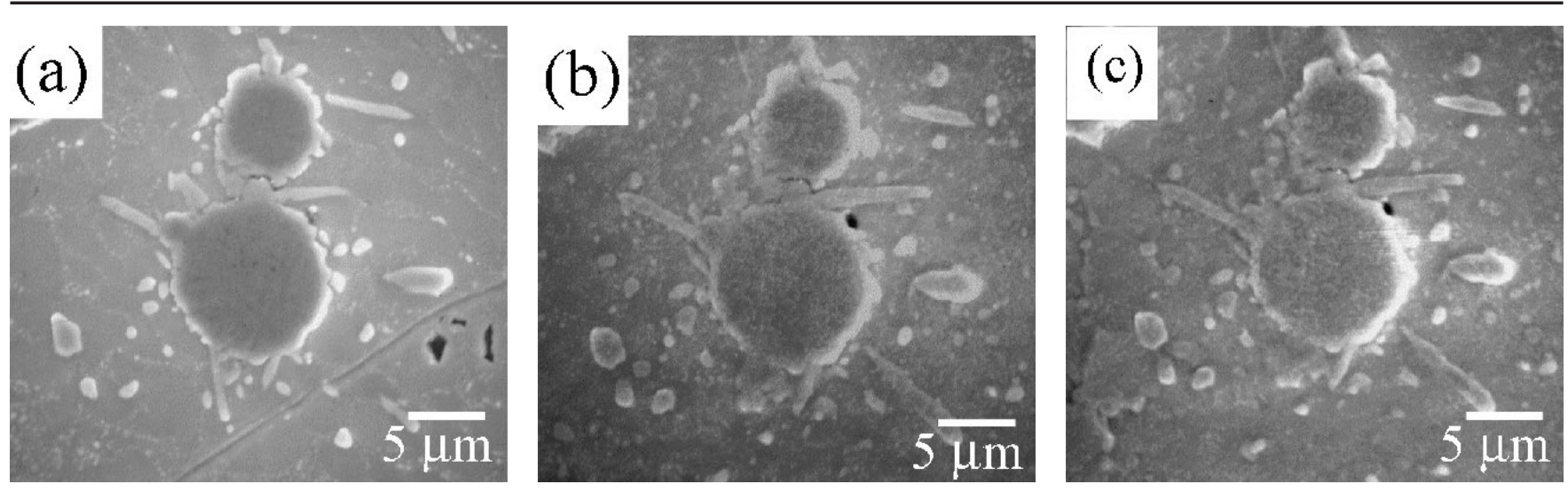

Fig. 4. The effect of isothermal aging at $200^{\circ} \mathrm{C}$ on the change of IMC morphology in the Ni-reinforced composite solder joint: (a) as-fabricated, (b) after $2 \mathrm{~h}$, and (c) after $20 \mathrm{~h}$. No change in IMC morphology can be noted. Note: fast heating rate and fast cooling rate.
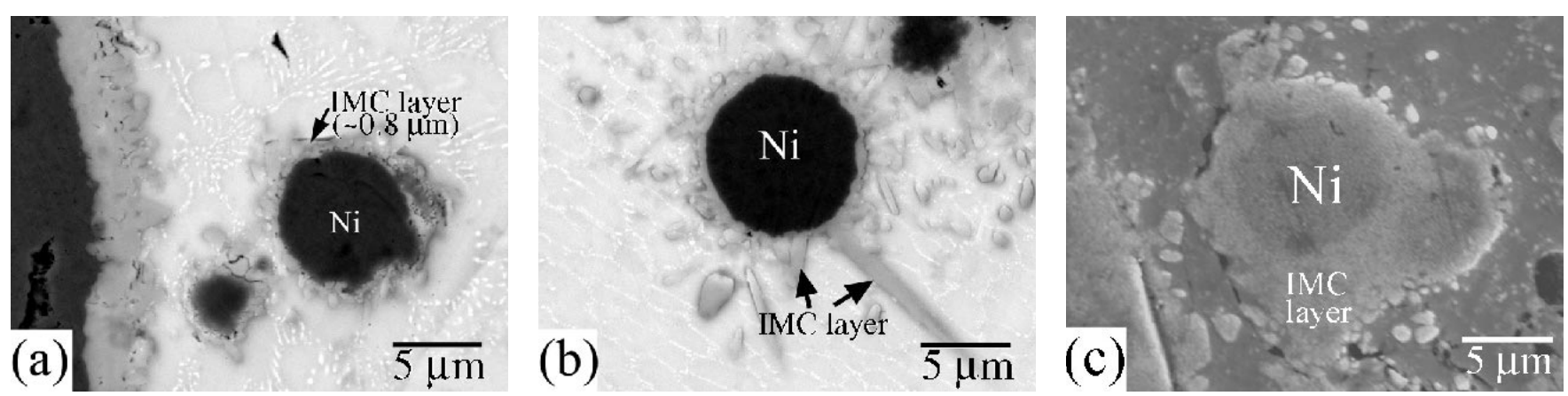

Fig. 5. The morphological changes in the IMC around Ni particles at $230^{\circ} \mathrm{C}$ : (a) $60 \mathrm{sec}$, (b) $180 \mathrm{sec}$, and (c) 270 sec. Note: fast heating rate and fast cooling rate.

The energy dispersive spectroscopy (EDS) of the IMC around Ni particles with increasing hold times at $230^{\circ} \mathrm{C}$ is provided in Fig. 6 . The very thin Ni- and Sn-containing IMC layer, formed initially at $230^{\circ} \mathrm{C}$ after $60 \mathrm{sec}$, was the Ni-Sn IMC layer (Fig. 6a). The thickness of this layer did not grow significantly after about 150 sec. Sunflower petal arms were formed around the Ni-Sn layer with increasing hold time at this temperature. The petals were mainly the $\mathrm{Cu}$-Sn IMC, as can be noted from the EDS line scan in Fig. 6b. Growth rate of the IMC with long petal arms that contain more $\mathrm{Cu}$ was much faster 

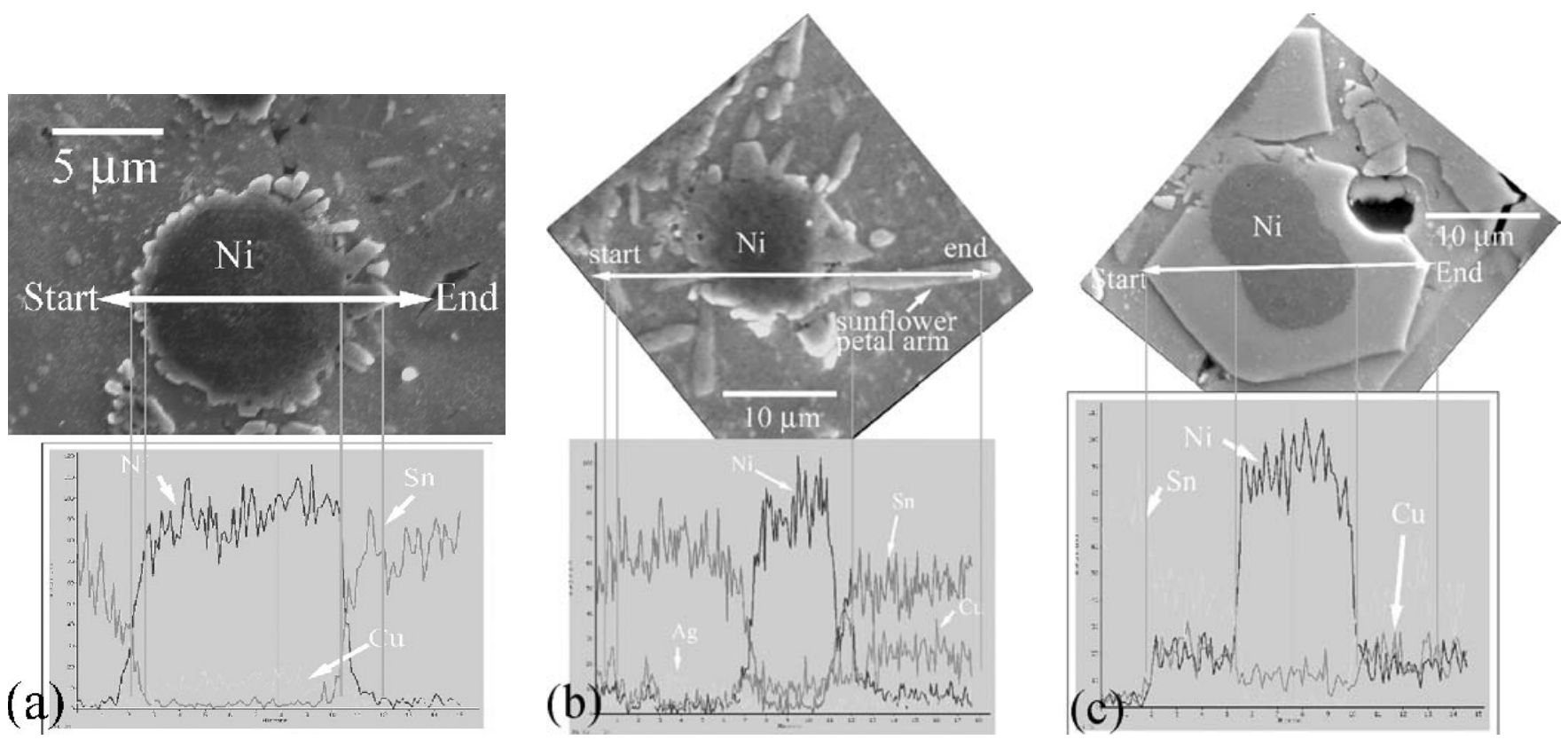

Fig. 6. The EDS of the IMC around Ni particles in Ni-composite solder joints aged at $230^{\circ} \mathrm{C}$. (a) For 60 sec, showing a very thin layer of IMC around the Ni particle. The EDS profile shows that this thin layer is the Ni-Sn IMC layer. (b) For 120 sec, start to form sunflower long petal arms with increasing hold times. The petal arms are mainly the Cu-Sn IMC layer with very insignificant amounts of Ni. (c) For 270 sec, ultimately showing blocky IMC, and the IMC is the Cu-Ni-Sn IMC. This layer is homogenized with almost same amounts Cu and Ni. Note: fast heating rate and fast cooling rate.

than IMC layer growth prior to the formation of these long petal arms. Longer hold times at this temperature resulted ultimately in blocky IMC morphology. In the blocky IMC, the $\mathrm{Cu}$ and $\mathrm{Ni}$ concentrations tend to be about the same because of homogenization, as can be seen in the EDS line scan in Fig. 6c. When the blocky IMC formed around Ni particles, the size of this IMC layer did not change significantly with increasing hold times at $230^{\circ} \mathrm{C}$. Similar IMC compositions were observed for aging at $250^{\circ} \mathrm{C}$. However, faster blocky IMC morphology formation was noted because of the higher temperature employed.

The growth of the IMC around Ni particles with different hold times at $230^{\circ} \mathrm{C}$ and $250^{\circ} \mathrm{C}$ is illustrated in Fig. 7. Initially, the thickness of this IMC is very thin $(\sim 1 \mu \mathrm{m})$. This thickness increased significantly with longer hold times to a limit of about $5 \mu \mathrm{m}$ in thickness. As can be seen in Fig. 7, the growth rate of the IMC, disregarding the shooting out petals, exhibits three stages. Activation energy calculated from this plot is listed in Table I. Stage I corresponds to formation of a very thin, Ni-Sn IMC layer and has a small slope with high activation

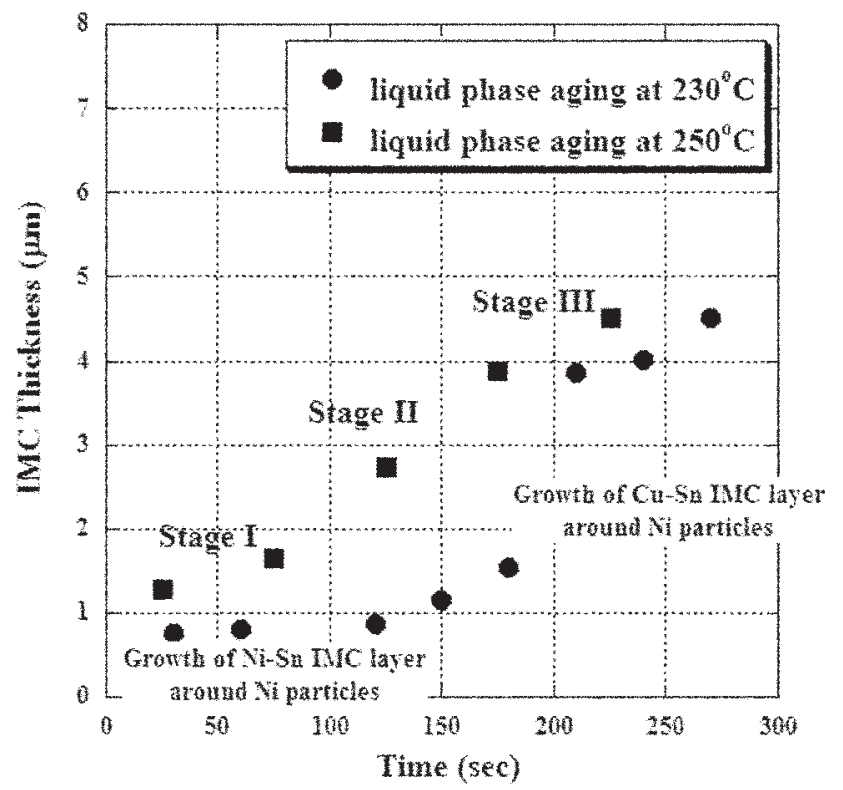

Fig. 7. The plots of the IMC thickness versus time around Ni particles in Ni-composite solder joints after aging in molten solder at $230^{\circ} \mathrm{C}$ and $250^{\circ} \mathrm{C}$. Note: fast heating rate and fast cooling rate.

Table I. Activation Energy of Intermetallic Compound Layer Growth around Ni Particles in Ni-Reinforced Composite Solder on a Cu Substrate in the Presence of Molten Solder

\begin{tabular}{|c|c|c|c|}
\hline Item & Ni-Sn Layer (Stage I) & Cu-Sn Layer (Stage II) & Cu-Sn Layer ${ }^{16}$ \\
\hline Activation energy (kJ/mole) & 47.8 & 18.2 & 17.6 \\
\hline
\end{tabular}

Note: The growth kinetics of the IMC layer was determined using a simple growth model, $d=d_{0}+\sqrt{K t}$ (where $d=$ IMC thickness at aging time $t, d_{0}=$ initial IMC thickness, and $\mathrm{K}=$ the layer-growth coefficient). Using the Arrhenius relationship in terms of $\mathrm{K}=\mathrm{A}$ exp $(-\mathrm{E} / \mathrm{RT}$ ), activation energy was calculated from the slope of $\ln \mathrm{K}$ versus $1 / \mathrm{T}$ plot. 


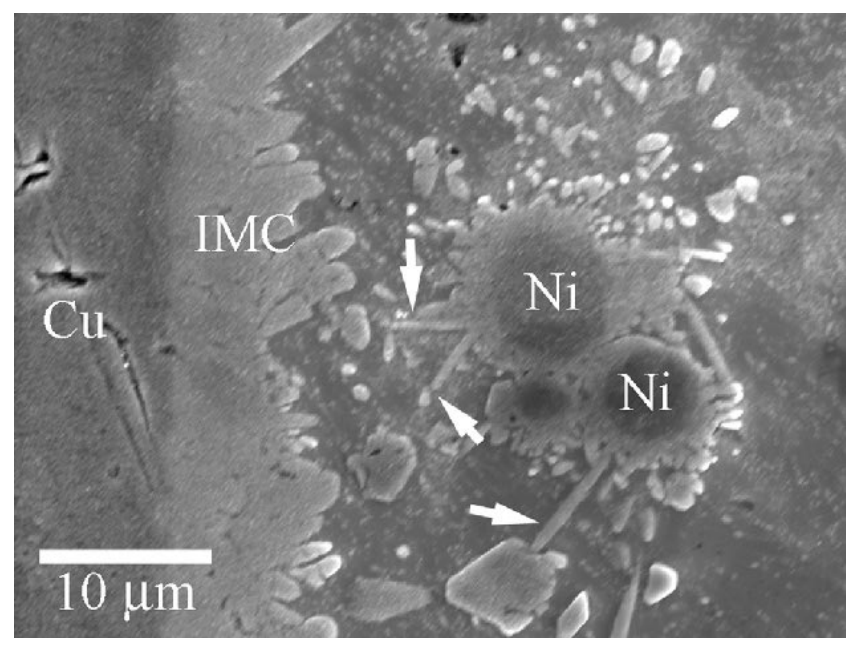

Fig. 8. The directional tendency in sunflower petal formation around $\mathrm{Ni}$ particles. Arrows indicates Cu-Sn petal IMC around Ni particles. Note: fast heating rate and fast cooling rate.

energy because of a very slow diffusion of $\mathrm{Ni}$ into the molten Sn-Ag solder. Stage II corresponds to formation of the Cu-Sn IMC layer, with longer hold time in molten solder, and has a steep slope with a low activation energy, corresponding to that for dissolution of $\mathrm{Cu}$ in molten $\mathrm{Sn}$ published in the literature. ${ }^{16}$ Stage III corresponds to the blocky IMC morphology, where homogenization takes place, and it has a smaller slope wherein no additional $\mathrm{Ni}$ or $\mathrm{Cu}$ may diffuse into this IMC layer. The sunflower long petals tend to grow toward the substrate where the source of $\mathrm{Cu}$ exists, as can be noted from Fig. 8. This indicates that $\mathrm{Cu}$ from the substrate influences the petal formation.

One could hypothesize that the ultimate size of the blocky IMC around $\mathrm{Ni}$ will be controlled by the limiting solid-state diffusion of $\mathrm{Cu}$ from the substrate through the solid $\mathrm{Cu}_{6} \mathrm{Sn}_{5}$ interface IMC layer.

Results of the x-ray diffraction studies are consistent with the above findings. They indicate that $\mathrm{Ni}$ particles form the $\mathrm{Ni}_{3} \mathrm{Sn}_{4} \mathrm{IMC}$ after prolonged aging in the presence of molten solder at high temperatures. Under such conditions, $\mathrm{x}$-ray peaks caused by Ni decrease with time, while those caused by Ni-Sn IMC increase with time. The presence of $\mathrm{Cu}$ particles along with Ni particles did not seem to influence the Ni-Sn IMC formation around Ni particles.

\section{Solder with Ag Particle Reinforcement}

At $230^{\circ} \mathrm{C}$, slightly above the melting temperature of eutectic $\mathrm{Sn}-\mathrm{Ag}$, the IMC morphology around $\mathrm{Ag}$ particles did not change even after aging for $30 \mathrm{~min}$ in molten solder (Fig. 9a).

\section{Solder with Cu Particle Reinforcement}

Unlike the $\mathrm{Ag}$ composite solder, the $\mathrm{Cu}$ particle was almost $100 \%$ consumed after aging at $230^{\circ} \mathrm{C}$, and the very thick layer of IMC formed around the $\mathrm{Cu}$ particles can be seen in Fig. 9b. Similar behavior was also noted in a Ni-composite solder joint after aging at $230^{\circ} \mathrm{C}$ for $30 \mathrm{~min}$, as illustrated in Fig. 9c. $\mathrm{X}$-ray studies indicate that the peaks caused by the $\mathrm{Cu}$ decrease and those caused by the $\mathrm{Cu}-\mathrm{Sn}$ IMC increase with time. Although this behavior is similar to that observed with $\mathrm{Ni}$ particle-reinforced solder, the events took place much faster.

\section{Reflow of the Ni-Composite Solder on the Ni Substrate}

The Ni-composite solder joints reflowed on the $\mathrm{Cu}$ substrate always resulted in sunflower IMC morphology around the $\mathrm{Ni}$ particles with fast heating and cooling rates. Copper was present in the IMC formed around the Ni particles even if this particle was far away from the Ni-composite solder/Cu substrate interface. To investigate the role of $\mathrm{Cu}$ that diffuses into the molten solder from the $\mathrm{Cu}$ substrate, the Ni-composite solder was reflowed on a $\mathrm{Ni}$ substrate, after briefly polishing and etching it to remove the oxide layer just prior to reflow. No sunflower
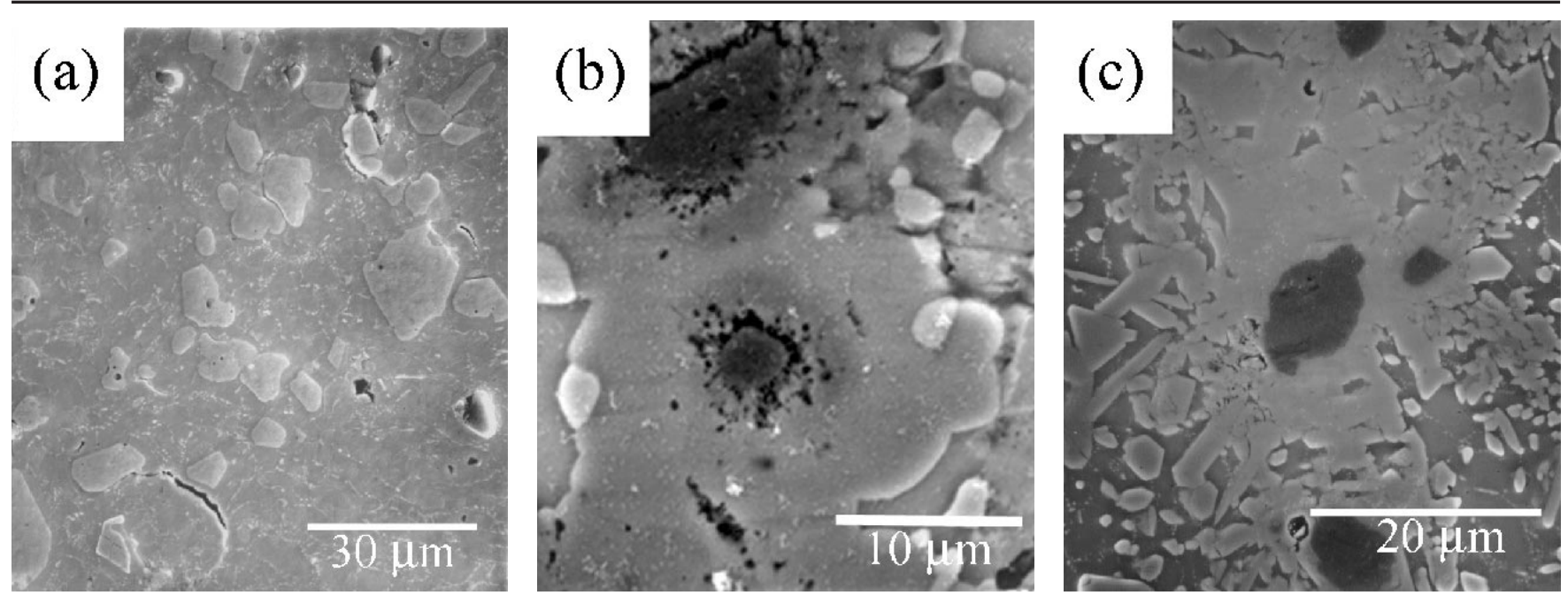

Fig. 9. The effect of isothermal aging at $230^{\circ} \mathrm{C}$ in the molten solder for $30 \mathrm{~min}$ : (a) Ag-composite solder, (b) Cu-composite solder, and (c) Ni-composite solder. Even in the presence of liquid solder, the Ag IMC morphology did not change. Note: fast heating rate and fast cooling rate. 

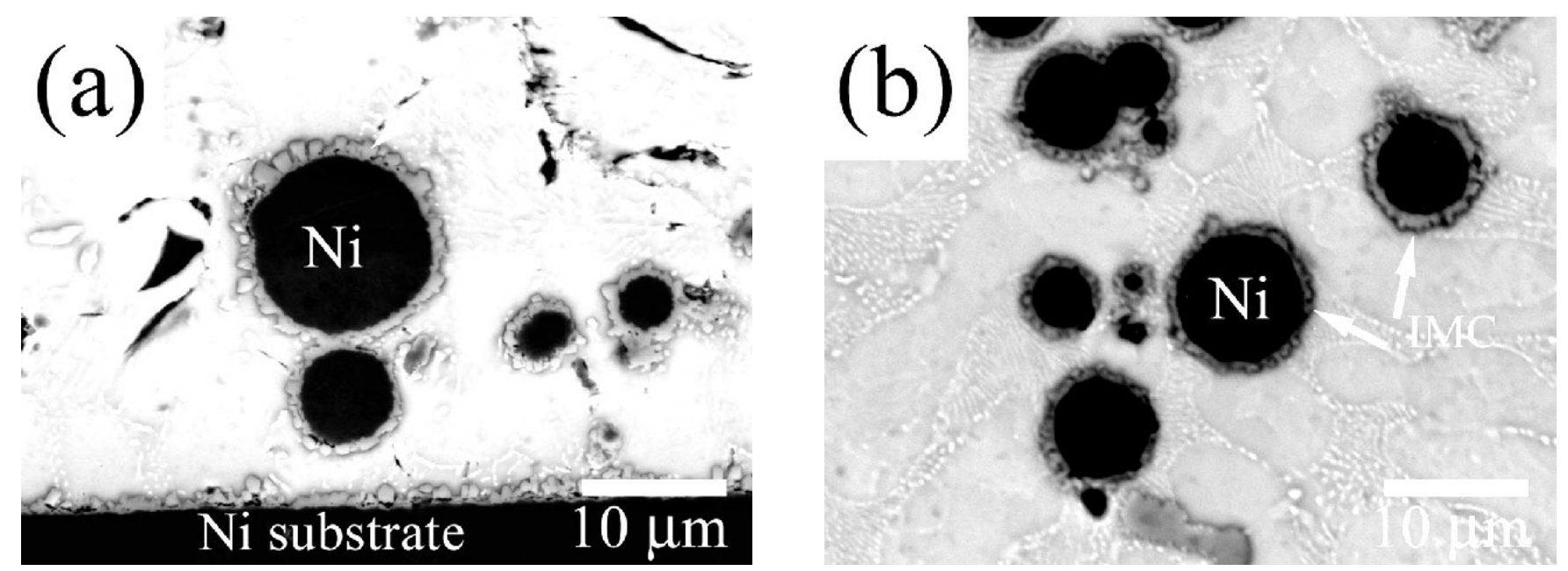

Fig. 10. The SEM images of the Ni-reinforced composite solder with Ni substrate. No sunflower morphology observed with fast heating rate and fast cooling rate: (a) Near Ni substrate and (b) away from Ni substrate. Note: the solder joints fabricated with fast heating rate and fast cooling rate.

morphology of the IMC around the $\mathrm{Ni}$ particles resulted with the $\mathrm{Ni}$ substrate, as can be seen in Fig. 10. Because no such sunflower IMC morphology is noted with reflow on the Ni substrate, a solder containing both $\mathrm{Ni}$ and $\mathrm{Cu}$ particles was reflowed on the Ni substrate with the same temperature profile. This produced a sunflower IMC morphology around the Ni particles. Solder containing both $\mathrm{Ni}$ and $\mathrm{Cu}$ particles reflowed on the Ni substrate exhibited long petalled, sunflower morphology around the Ni particles, as illustrated in Fig. 11a. In the solder area, having both $\mathrm{Ni}$ and $\mathrm{Cu}$ particles close together, the IMC morphology around the Ni particle is sunflower (Fig. 11b), and the long petal arms of this sunflower has $\mathrm{Cu}$ with $\mathrm{Ni}$ and Sn. Thus, the IMC around the Ni particle is ternary Ni-Cu-Sn. However, no $\mathrm{Ni}$ was noted in the $\mathrm{IMC}$ around the $\mathrm{Cu}$ particle, indicating $\mathrm{Ni}$ did not diffuse and enter the IMC layer around $\mathrm{Cu}$ particles. Copper is also present at the IMC $\mathrm{Ni}+\mathrm{Cu}$ composite solder/Ni substrate interface in these solder joints, as can be noted from the EDS line scan in Fig. 11d. The $\mathrm{Cu}$ diffuses very fast in liquid solder and forms the IMC with the Ni substrate. In $\mathrm{Ni}+\mathrm{Cu}$ particle-reinforced solder with the Ni substrate, the petals in sunflower morphology around the Ni particles are the $\mathrm{Ni}-\mathrm{Cu}-\mathrm{Sn} \mathrm{IMC}$, but the presence of $\mathrm{Ni}$ in these petals is relatively insignificant.

\section{Observation of Solder/Ni Substrate Intermetallic Compound Interface in the $\mathrm{Ni}$ - Composite and $\mathrm{Ni}+\mathrm{Cu}$ Composite Solder Joints}

The Ni-composite solder/Ni substrate and $\mathrm{Cu}+\mathrm{Ni}$ composite solder/Ni substrate interfaces exhibit the features illustrated in Fig. 12. As can be noted in Fig. 12a, these IMC layers are a very thin chunky shape, as has been documented in published literature. ${ }^{17}$ The morphology of this IMC layer is similar to that found around the $\mathrm{Ni}$ particle when $\mathrm{Cu}$ is not available in the system to form the petals, as can be seen in the insert SEM image in Fig. 12a.
The IMC interface layer of solder joints made with the $\mathrm{Ni}+\mathrm{Cu}$ composite solder on the $\mathrm{Ni}$ substrate presents long petal arms from the IMC interface layer, as noted in Fig. 12b. These long petal arms contain $\mathrm{Ni}$ and $\mathrm{Sn}$ as well as $\mathrm{Cu}$. Copper from added particles can participate in IMC formation at the $\mathrm{Ni}+\mathrm{Cu}$ composite solder/Ni substrate interface during reflow and make long petal arms similar to those formed around $\mathrm{Ni}$ particles in the $\mathrm{Ni}$ composite solder reflowed on the $\mathrm{Cu}$ substrate. This behavior suggests that $\mathrm{Cu}$ from either $\mathrm{Cu}$ substrate or $\mathrm{Cu}$ metallic particles can diffuse very fast in the molten Sn-based solder and react with the Ni-Sn IMC, resulting in long petal arms. Higher $\mathrm{Cu}$ and minimal Ni concentrations are noted in long petal arms.

\section{SUMMARY}

The IMC morphology around Ni particle reinforcement in eutectic $96.5 \mathrm{Sn}-3.5 \mathrm{Ag}$ solder, in the presence of a $\mathrm{Cu}$ source, depends on the reflow and aging conditions employed. Under such conditions, with fast heating and fast cooling rates, a thin $\mathrm{Ni}-\mathrm{Sn}$ layer forms around the $\mathrm{Ni}$ particle followed by the development of petals containing $\mathrm{Cu}$ and $\mathrm{Sn}$. Repeated reflows with fast heating and cooling rates, slow heating rates, or increased time and temperature above the solder liquidus temperature during reflow change the IMC morphology into a blocky one. This blocky IMC consists of $\mathrm{Ni}, \mathrm{Cu}$, and $\mathrm{Sn}$.

In the absence of a copper source, either from the substrate or from $\mathrm{Cu}$ particulates within the solder, blocky IMC that forms around the Ni particles does not exhibit the petal morphology. The morphology of the IMC around $\mathrm{Cu}$ particulates in eutectic Sn-3.5Ag solder is scallop shaped. The IMC layer thickness increases with repeated reflows or with increased time and temperature above the solder liquidus without any morphological changes.

The Ag particles present in the Sn-3.5Ag solder develop a thin IMC layer during reflow, and 

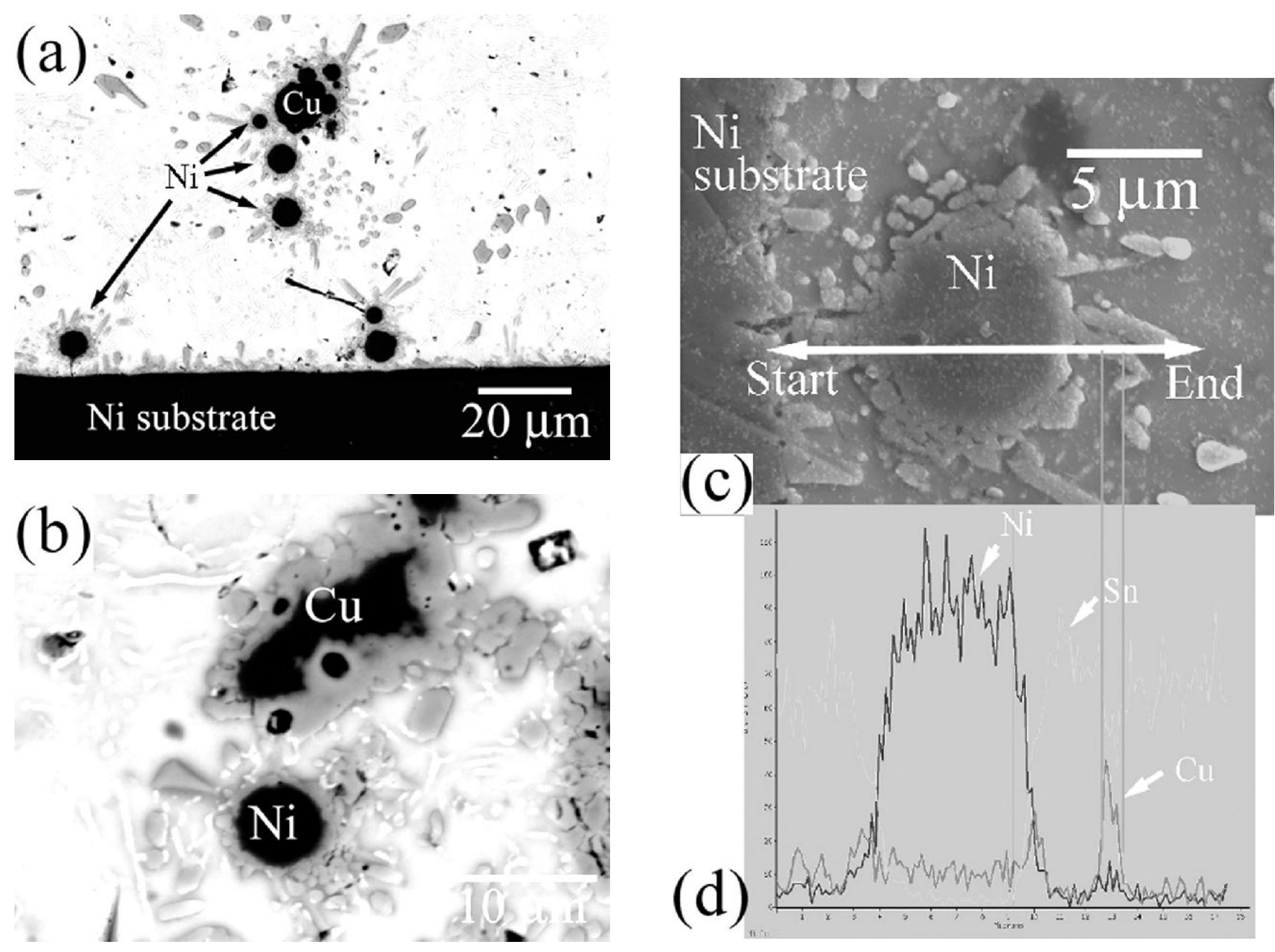

Fig. 11. The $\mathrm{Ni}+\mathrm{Cu}$ particles reinforced composite solder on the Ni substrate: (a) low-magnification SEM image, (b) SEM image showing sunflower IMC morphology around $\mathrm{Ni}$ caused by diffusion of $\mathrm{Cu}$ from the nearby Cu particle, (c) IMC around the Ni particle showing a sunflower shape with a white line indicating location of the EDS line scan, and (d) an EDS line scan showing Cu diffusion from Cu particles. Note: the solder joints fabricated with fast heating rate and fast cooling rate.
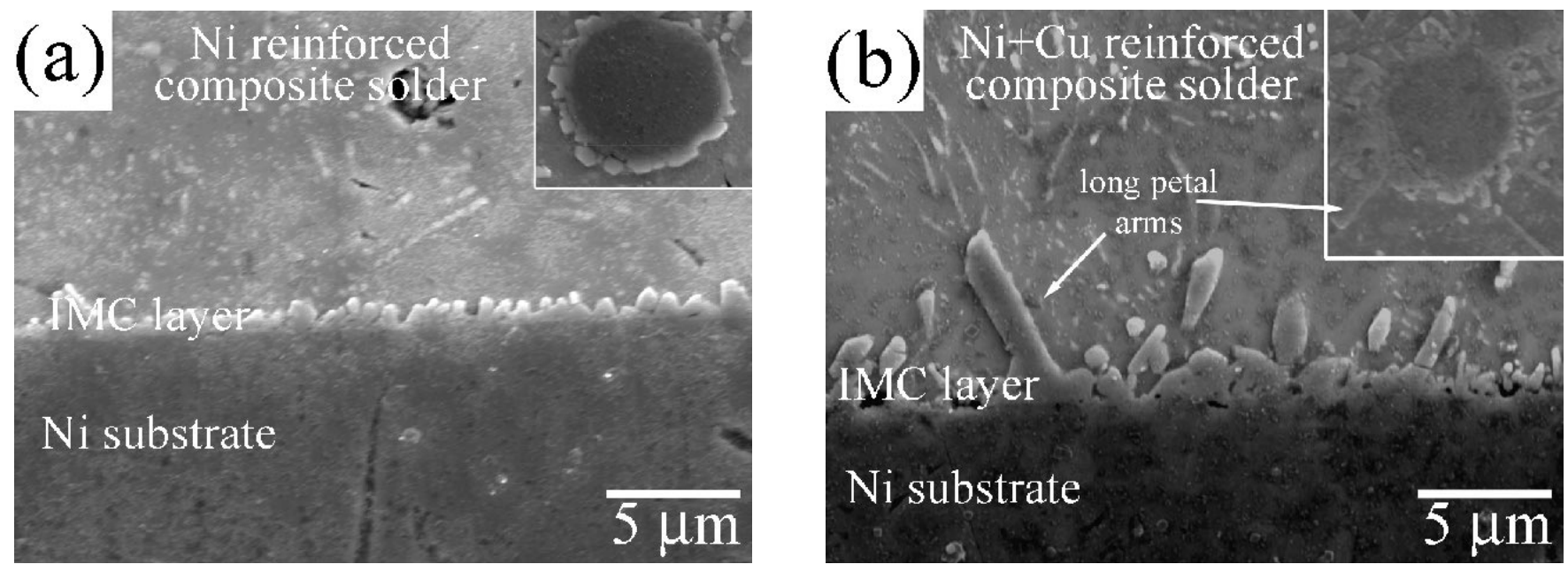

Fig. 12. The SEM micrographs of solder reflowed on Ni substrate: (a) Ni-reinforced composite solder and (b) Ni + Cu composite solder. In both micrographs, the insert image is that of the Ni particle and the IMC around it. The IMC around the Ni particle exhibits the same morphology of the IMC formed at the solder/Ni substrate interface. Note: the solder joints fabricated with fast heating rate and fast cooling rate. 
this layer does not grow or exhibit any morphological changes irrespective of the reflow conditions employed.

\section{ACKNOWLEDGEMENTS}

The authors thank the National Science Foundation (NSF) for the financial support of this work under Contract No. NSF-DMR-0081796. The NSF has provided an RUI grant for Dr. Chen's participation.

\section{REFERENCES}

1. M. Nishiura, A. Nakayama, S. Sakatani, Y. Kohara, K. Uenishi, and K.F. Kobayashi, Mater. Trans. 43, 1802 (2002).

2. K. Uenishi, Y. Kohara, L. Sakatani, T. Saeki, K.F. Kobayashi, and M. Yamamoto, Mater. Trans. 43, 1833 (2002).

3. S.K. Kang, W.K. Choi, M.J. Yim, and D.Y. Shih, J. Electron. Mater. 31, 1291 (2002).

4. S. Ahat, W.D. Huang, S. Mei, and L. Le, J. Electron. Mater. 31,136 (2002).
5. C.M.L. Wu and M.L. Huang, J. Electron. Mater. 31, 442 (2002).

6. S. Choi, K.N. Subramanian, J.P. Lucas, and T.R. Bieler, J. Electron. Mater. 29, 1259 (2000).

7. C. Kanchanomai, Y. Miyashita, Y. Mutoh, and S.L. Mannan, Mater. Sci. Eng. A 345, 90 (2003).

8. S.Y. Hwang, J.W. Lee, and Z.H. Lee, J. Electron. Mater. 31, $1304(2002)$

9. S. Choi, T.R. Bieler, J.P. Lucas, and K.N. Subramanian, J. Electron. Mater. 28, 1209 (1999).

10. D. Lin, G.X. Wang, T.S. Srivatsan, M. Al-Hajri, and M. Petraroli, Mater. Lett. 53, 333 (2002).

11. S.G. Jadhav, T.R. Bieler, K.N. Subramanian, and J.P. Lucas, J. Electron. Mater. 30, 1197 (2001).

12. F. Guo, J.G. Lee, S. Choi, J.P. Lucas, T.R. Bieler, and K.N. Subramanian, J. Electron. Mater. 30, 1073 (2001).

13. J.G. Lee, F. Guo, K.N. Subramanian, and J.P. Lucas, Solder. Surf. Mount Technol. 14, 11 (2002).

14. F. Guo, J.G. Lee, S. Choi, J.P. Lucas, T.R. Bieler, and K.N. Subramanian, J. Electron. Mater. 30, 1073 (2001).

15. F. Guo, S. Choi, J.P. Lucas, and K.N. Subramanian, Solder. Surf. Mount Technol. 13, 7 (2001).

16. C.H. Ma and R.A. Swalin, Acta Metall. 8, 388 (1960).

17. J.W. Jang, P.G. Kim, and K.N. Tu, J. Appl. Phys. 85, 8456 (1999). 